\title{
A Throughput Time Study on Gemba through ABC Analysis for High Demand Product among Varieties of Products
}

\author{
Raj Mohan R ${ }^{1}$, V.Senthil Kumar ${ }^{2}$ \\ 1,2 Department of Mechanical Engineering , TRP Engineering College (SRM Group) Trichy, Tamil Nadu
}

\begin{abstract}
Today companies are still tolerating an indecisive future due to apathetic consumer demand and rising product prices. Reductions in manufacturing throughput time reduce the time required to respond to customer orders. Throughput time influenced by mainly two elements called cycle time and inventory. The aim of the paper is to reduce throughput (flow) time through decrease in cycle or process time of bottleneck machines and work in process inventory. The physical tracking study conducted on the high demand product among various products based on average daily requirement on Gemba i.e. workplace through ABC Analysis. Avoidance of starvation and blocking can be improved through reduction in flow time. This leads to achieve the customer demand in time, increase the productivity and to reduce the cost incurred during the process.
\end{abstract}

Keywords - Cycle time, Inventory, Productivity, Throughput time, Customer Demand

\section{Introduction}

Throughput time is a time elapsed required for a raw material or sub-assembly to let through a manufacturing process following the release of an order to the manufacturing gemba. Throughput time consists of process time, quality inspection time, transportation time and waiting time. Process time is the time period during which work is performed on the product itself. Inspection time is the time during which the quality of the product is confirmed. Transportation time is the time during which materials or works-in-process are moved from one workstation to another. Queue time is the phase of time during which the product awaits transfer to a workstation, undergoes further inspection and succeeding manufacturing processes. Reductions in manufacturing throughput time increase flexibility and reduce the time required to respond to customer orders. This can be vital to the survival and profitability of numerous firms, especially those experiencing increased market pressures for shorter delivery lead times of customized product [1]. This is essential to survive in the present competitive market where in the costs are major concerns. Therefore, in order to remain competitive, waste from inventory must be identified and eliminated so to run system with maximum efficiencies [2]. Storage space by way of a "buffer" is provided in between each pair of work stations in order to temporarily hold work in process (WIP) items. The function of the buffers is to help avoid production stoppage when a worker is deprived of having a work piece to process (known as "starving"), or is unable to pass an item on to the succeeding station due to lack of space (known as "blocking") . Throughput, utilization, and cycle time continue to be emphasized as key performance parameters for existing operations and for the complex planning of new facilities [3]. To increase plant throughput, changes that increase the batch size or reduce the plant cycle time can be effective [4]. This paper first to point up the basic elements that determine manufacturing throughput time.

The Objectives of the investigation, therefore, are to;

- Increase Productivity

- $\quad$ Reduce throughput time

- $\quad$ Avoid starvation and blocking

- $\quad$ Achieve customer demand in time

\section{A. Selection of Problem}

\section{METHODOLOGY}

$\mathrm{ABC}$ Analysis is a thumb rule of Quality Control Story. 'A' Denotes Solving the problem by team or ourselves, 'B' denotes solve with other departments, ' $C$ ' denotes solve with management for example in Design phases. Here, Problem can be solved by team or self because it doesn't obstruct flow process in gemba ('A' analysis) and its takes time to track down i.e. physical tracking the product flow from all modules to main assembly to customer dispatch and subsequently ' $\mathrm{B}$ ' analysis is carried out to find solutions for high machine cycle time in cell and inventory between workstations. Selection of problem from problem bank based on the impact of 
productivity, quality, cost, delivery, safety, that point out the throughput time for running product can't meet customer demand in gemba.

\section{B. Data Collection}

Data should focus on problem features like period / time, place, type of symptoms as indicated in Fig. 1.This shows that product has to move from four different modules to main assembly and to customer dispatch, it should be noted that module ' 3 ' has high throughput time to reach main assembly.
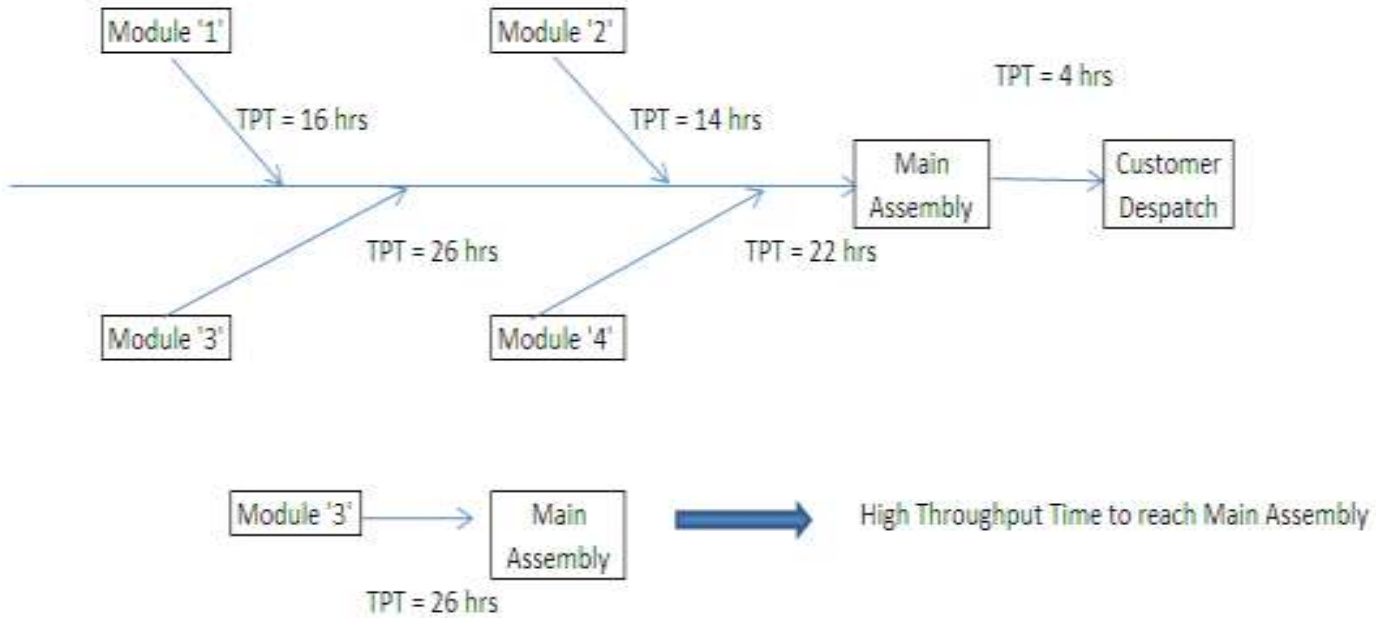

Fig. 1 Throughput time of product through physical tracking

\section{Analysis}

To identify all possible causes for high throughput time through brainstorming method. Root cause for High throughput time is

1. Waiting time between two stations.

2. Processing of other products than running product in same machine.

3. Workers idle time due to machine breakdown, waiting for first off inspection result, taking break than allowed time, unnecessary motions from one machine to another machines.

Blocking and starvation occurs leads to increase in Work in process inventory between stations and cycle time of bottleneck machines in cell also affects throughput time. Bottleneck machines are known as low capacity machines among various machines in a cell for a particular product. It leads to affect the TAKT time.

\section{Action}

Another improvement towards prevention was to learn from errors in the past and make impact on productivity, quality, cost, delivery and safety. This means that an out of control situation should not only lead to solving this specific occurrence of the problem, but also to more structural improvements that can prevents this kind of problem in the future. After finding the causes for critical issues through ABC Analysis, suggestions are provided for avoidance of these major issues of high throughput time.

\section{E. Check}

After the implementation of action Plan, Worker idle time is reduced from $30 \%$ to $13 \%$ and avoiding the processing of other products than running product as much extent. Cycle time is reduced from 32 seconds to 24 seconds by following Standard operating procedures properly and applying low automation techniques in bottleneck machines as cited in Fig. 2 and Fig. 3 respectively. After implementing action plan to module ' 3 ' for reducing high throughput time and horizontally deploy these action plan to all modules. As a result subsequent improvement obtained in throughput time reduction as indicated in Fig. 4. 


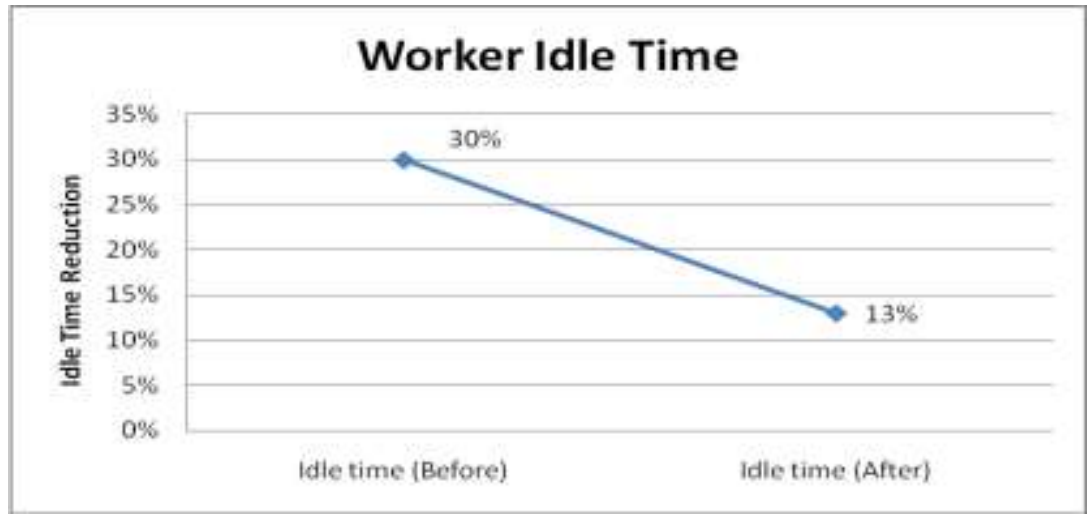

Fig. 2 Reduction in Worker Idle time

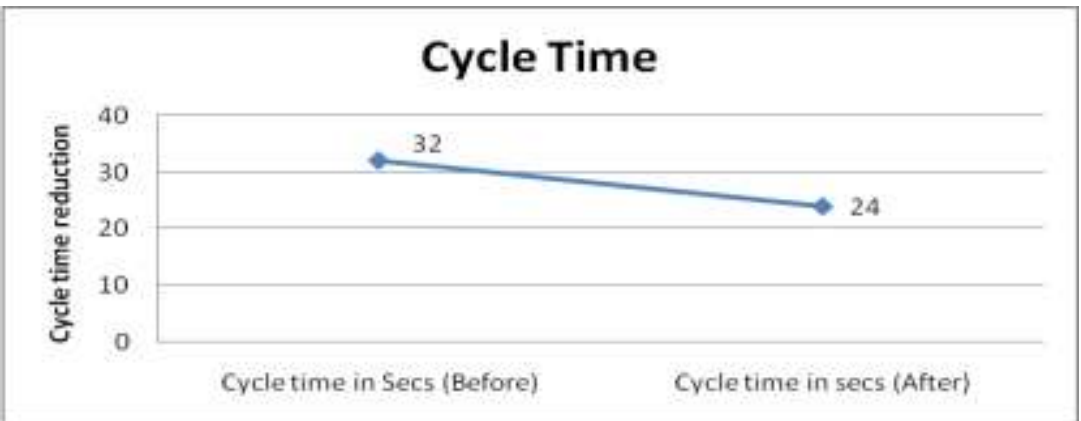

Fig. 3 Reduction in Cycle time

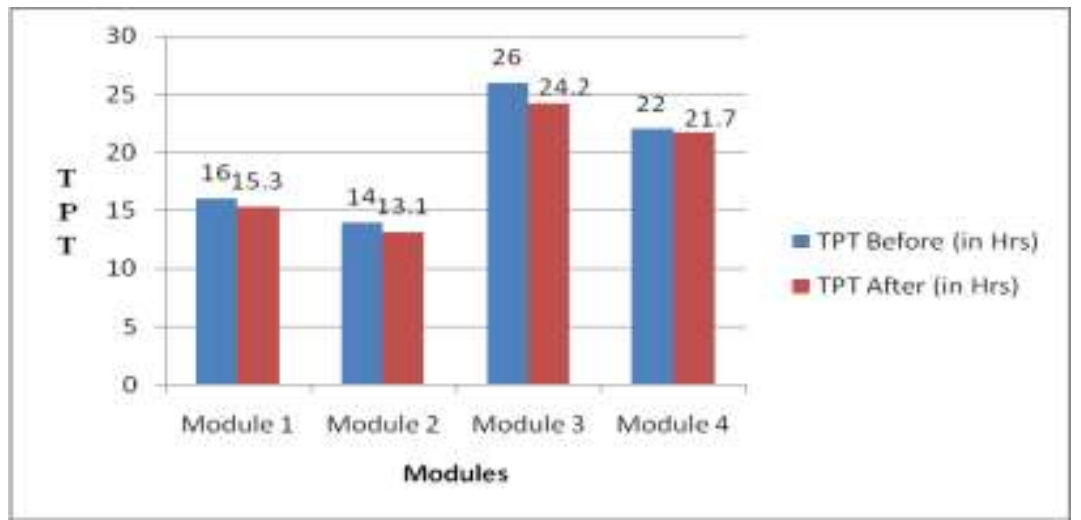

Fig. 4 Reduction in Throughput time

III. Conclusion

Finally, concluded that Physical tracking approach is an effective means for improving the productivity and delivery and noted that can make substantial improvement in Throughput time reduction. This result provides convincing evidence that eliminating some non value added activities like waiting time, idle time, etc., in Gemba leads to an continuous improvement in process.

\section{References}

[1] Danny J. Johnson, “A Framework for Reducing Manufacturing Throughput Time,” Journal of Manufacturing Systems, Vol. 22/No. 4 , pp. 283-298, 2003.

[2] Rajeev Choudhary, Pushpinder Kaushik, Neeraj Nirmal and Vinod Dhull, "An empirical study on role of Lean Manufacturing in manufacturing industry,” International Journal on Emerging Technologies, Issue No : 3(1), pp. 185-192, 2012.

[3] Steven Brown, Joerg Domaschke, and Franz Leibl , "No Cost' Applications For Assembly Cycle Time Reduction", International Conference on Semiconductor Manufacturing Operational Modeling and Simulation , pp. 17-20, 1999

[4] Minnich, T.M., "Use Process Integration for Plant Modernization," Chem. Eng., pp. 70-76, 2000. 